\title{
The relationships between some measures of the galvanic skin response
}

\author{
R. H. C. BULL and A. GALE*
}

University of Exeter, Washington Singer Laboratories, Exeter, Devon, England

The within-S reliabilities of and interrelationships between various aspects of the GSR were examined. Response magnitude, latency, and recovery were found to be reliable, but recruitment was not. Latency, recruitment, and recovery each correlated highly with magnitude. Recruitment and recovery correlated with each other, but neither correlated with latency.

There have been few attempts to interrelate the various aspects of the GSR, even though several of these measures (e.g., latency, magnitude, recruitment, and recovery) are easily obtained. Latency and magnitude are frequently measured, but recruitment (the time from response onset to peak) and recovery (the percentage of response magnitude recovered in a certain time) are not. The apparent lack of interest in the last two parameters is surprising, since they are both integral parts of the response. Using interindividual analysis, Wittig \& Wickens (1966) and Coles (1970) found short latencies to be associated with large magnitudes. Uno \& Grings (1964) found large magnitudes to be associated not only with short latencies but also with long recruitment times. Wolfensberger \& O'Connor (1967) reported modest correlations between these three measures. In such experiments, each individual was subjected to only a single experimental session, and consequently the interrelationships obtained may have been specific to the period of observation and not an enduring aspect of the individual's physiological functioning. Little investigation has been undertaken into the intra-S reliability of these measures. However, Freeman \& Griffin (1939), Lacey \& Lacey (1962), and Block (1965) did find response magnitude to be reliable over time. In the present experiment, responses are obtained from each of several individuals over a considerable number of days.

\section{METHOD}

The Ss were 15 ( 8 male, 7 female) student volunteers. The same stimulus (a 90-dB $1,000-\mathrm{Hz} 2$-sec tone) was presented 10 times to each of them, the tone being presented only once at each test session and there being an interval of 3 to 6 days between each of the 10 sessions. Exosomatic electrodermal activity was recorded from the volar surface of the middle

* Now at University College of Swansea. and index fingers of the nonpreferred hand. A constant current of 8 microA was passed between silver/silver chloride electrodes which were $1 \mathrm{sq} \mathrm{cm}$ in area. $0.05 \mathrm{M} \mathrm{NaCl}$ electrode jelley was used, and the electrodermal activity was recorded on UV paper with a sensitivity of $250 \mathrm{ohms} / \mathrm{mm}$ and a speed of $6 \mathrm{~mm} / \mathrm{sec}$. Only resistance changes greater than 250 ohms were extracted from the record, and the temporal aspects of the GSRs were measured to the nearest 10 th of a second. Once the electrodes were attached, the $S$ was led into a soundproof room where he reclined on a bed and earphones were placed over his head. (A constant temperature of $25^{\circ} \mathrm{C}$ was maintained in the soundproof room throughout the experiment.) A few seconds after the $\mathrm{E}$ left the room, the tone was delivered. The first decrease in resistance which occurred within $6 \mathrm{sec}$ of stimulus onset was deemed as the response to that stimulus. The magnitude of this response was the difference between the resistance level at response onset and the lowest resistance level reached before a subsequent increase in resistance. Where a second deflection occurred in the trace before the first wave had returned to its prestimulus level, this second inflection was not counted as part of the response to the tone. Recovery was defined as the percentage of the response magnitude which was recovered within $2 \mathrm{sec}$ of the response peak. If a second inflection occurred within $2 \mathrm{sec}$ of the response peak, the recovery quotient could not be determined.

\section{RESULTS}

Only two Ss (both female) failed to respond to each presentation of the tone. One failed to respond on her seventh attendance, the other on her eighth. Their data are not included in the analysis. The following discussion is therefore concerned with $13 \mathrm{Ss}$ only. Friedman nonparametric analyses of variance were performed to determine the within-S reliability of the GSR parameters. Latency $\left(x^{2}=37.5, \quad p<.001\right)$, magnitude $\left(x^{2}=23.0, \quad p<.05\right)$, and recovery $\left(x^{2}=29.4, p<.01\right)$ were found to be reliable, but recruitment $\left(x^{2}=10.3\right.$, $\mathrm{p}>.05$ ) was not. The interrelationships between the various aspects of the GSR were examined on an intraindividual basis rather than on the more gross basis of correlating group mean scores (Wittig \& Wickens, 1966; Coles, 1970). Within-S Spearman rank correlations were computed, since the data were not necessarily normally distributed. Table 1 summarizes the results.

\section{DISCUSSION}

The latency, magnitude, and recovery aspects of the GSR appear to be reliable. Previous studies have shown not only that magnitude is a stable measure within Ss, but also that it is correlated with latency. Therefore, the demonstration of within-S reliability of GSR latency is not unexpected. The finding that recruitment time was not constant within Ss has already led to a further investigation being undertaken in this laboratory. The present study tends to confirm that latency is related

Table 1

A Summary of the Results of Within-S Spearman Rank Correlations Between Various Aspects of the GSR

\begin{tabular}{|c|c|c|c|c|c|}
\hline \multirow{2}{*}{$\begin{array}{c}\text { Within-S Correlation } \\
\text { of Measures }\end{array}$} & \multicolumn{2}{|c|}{$\begin{array}{l}\text { In Favor of } \\
\text { the Relationship }\end{array}$} & \multicolumn{2}{|c|}{$\begin{array}{l}\text { Against } \\
\text { the Relationship }\end{array}$} & \multirow[b]{2}{*}{$\mathbf{N}$} \\
\hline & Sig. & NS & Sig & NS & \\
\hline $\begin{array}{l}\text { Small response magnitude } \\
\text { and long latency }\end{array}$ & 2 & 11 & 0 & 0 & 13 \\
\hline $\begin{array}{l}\text { Small response magnitude } \\
\text { and short recruitment time }\end{array}$ & 4 & 6 & 0 & 3 & 13 \\
\hline $\begin{array}{l}\text { Small response magnitude } \\
\text { and large amount of recovery }\end{array}$ & 2 & 11 & 0 & 0 & 13 \\
\hline $\begin{array}{l}\text { Long latency and short } \\
\text { recruitment time }\end{array}$ & 1 & 4 & 1 & 7 & 13 \\
\hline $\begin{array}{l}\text { Long latency and large } \\
\text { amount of recovery }\end{array}$ & 1 & 7 & 2 & 3 & 13 \\
\hline $\begin{array}{l}\text { Short recruitment time and } \\
\text { large amount of recovery }\end{array}$ & 6 & 7 & 0 & 0 & 13 \\
\hline
\end{tabular}


to response magnitude in that small responses have long latencies. Of the 13 correlations computed, all were positive ( $\mathrm{p}<.001$, by sign test). As would be expected, small responses have short recruitment times $(p<.05$, by sign test). Percentage recovery within 2 sec appears to be related to response magnitude in that large responses tend to recover less during this period than do small GSRs (p<.001, by sign test). According to Wenger (1966), anxious Ss have "a generalized excessive reaction in the SNS." If this is the case, then given the constant stream of stimulation characteristic of everyday life, the finding that large GSRs recover only slowly suggests the hypothesis that anxious people have little opportunity to recover fully. Though latency was found to be related to magnitude and magnitude to recovery, latency does not appear to be related to recovery. Recruitment time, even though unreliable, seems to be related to magnitude and to recovery $(p<.001$, by sign test), but not to latency. In conclusion, investigations that attempt to relate electrodermal activity to other aspects of behavior may bear more fruit if their focus is not exclusively tied to the magnitude aspect of the GSR.

\section{REFERENCES}

BLOCK. J. D. Stimulus discrimination among autonomic measures: Individual and group characteristics. Psychosomatic Medicine. 1965, 27, 21 2-228.

COLES, M. G. H. Individual differences in relation to measures of attention and arousal. Unpublished doctoral thesis, University of Exeter, 1970.

FREEMIAN. G. L., \& GRIFFIN, L. L. The measurement of general reactivity under basal conditions. Journal of General Psychology, 1939, 21, 63-72.

LACEY, J. I., \& LACEY, B. C. The law of initial value in the longitudinal study of autonomic constitution: Reproducibility of autonomic responses and response patterns over a four year interval. Annals of the New Yodk Academy of Science, 1962, 98 . 1257-1290.

UNO, T.. \& GRINGS, w. W. Autonomic components of orienting behaviour. Psychophrsiologv, 1964, 1, 311-321.

WENGER. M. A. Studies of autonomic balance: A summary. Psychophysiology, 1966, 2. $173-186$.

WITTIG, A. F., \& WICKENS, D. D. Latency and magnitude of GSR as a function of interstimulus interval. Journal of Experimental Psychology, 1966, 71 . 466-467.

WOLFENSBERGER, W.. \& O'CONNOR, N. Relative effectiveness of galvanic skin response latency, amplitude arid duration scores as measures of arousal and habituation in normal and retarded adults. Psychophysiology, 1967, 3, 345-350. 